\title{
UN NUEVO MAPA DE EUROPA: CONCEPTOS, REPRESENTACIONES Y PERCEPCIONES DEL PROCESO DE CONSTRUCCIÓN POLÍTICA CONTINENTAL
}

Francisco LÓPEZ PALOMEQUE

Universidad de Barcelona

\section{PRESENTACIÓN}

En los dos últimos años se asiste a una nueva aceleración del proceso de construcción de la Unión Europea (UE) y ello ha provocado que de nuevo los medios de comunicación se ocupen de manera continua y destacada de este proceso. El "penúltimo" ejemplo lo constituye el monográfico que La Vanguardia ha dedicado en su colección Dossiers a "Qué quiere ser Europa" (AA.VV. 2003). Las preguntas como ¿qué es Europa?, ¿hasta donde llegan sus límites? o ¿cuáles han de ser los principios constituyentes de la "nueva" Unión Europea?, son interrogantes que alimentan el debate sobre este tema; debate recurrente en las dos últimas décadas, que inicialmente es de naturaleza política aunque, en realidad, trasciende esta condición y en él se implican otras dimensiones y otros argumentos (geográficos, sociales, culturales, educativos, ....). Como hechos más significativos de la aceleración del proceso de construcción política europea cabe señalar la cumbre de Copenhague de diciembre de 2002, donde la Unión Europea de los 15 aprobó una nueva fase de ampliación para 10 miembros más; y, por otra parte, la redacción en 2003 de la primera Constitución de la UE.

Los cambios de la estructura política de Europa suponen obviamente cambios en el mapa geopolítico del Viejo Continente, conformando un nuevo mapa que ilustra, desde una perspectiva histórica, el carácter cambiante del mismo. La aceptación de estas afirmaciones implica, a su vez, formular dos hipótesis:

1. El nuevo mapa político dibujado en los años 2002 y 2003 no será el último, ya que la estructura política de Europa es dinámica y, por lo tanto, el proceso de construcción de la UE es un proceso inacabado, sin contar además con otros posibles procesos políticos y con los cambios que puedan producirse a otros niveles de organización político/ administrativa diferentes al Estado.

2. El abordar la formación del nuevo mapa político de Europa, como representación de su nueva estructura política, requiere considerar otros 
procesos, otras realidades y otras representaciones que contextualizan o enmarcan las transformaciones de dicha estructura política y que permiten determinar con mayor rigor -a modo de factor explicativo- el significado y alcance de los cambios. En consecuencia, para fundamentar estas premisa convendrá considerar los conceptos de Europa y sus representaciones cartográficas.

La palabra Europa ha sufrido, está sufriendo, un desplazamiento semántico de primera magnitud; en las últimas décadas, y muy particularmente en los últimos años, la palabra Europa se ha desplazado del pasado hacia el futuro y de la geografía hacia la política (CABRÉ Y DOMINGO, 1991, 28). La idea de Europa como realidad o como proyecto político es la dominante en la interpretación y el discurso sobre lo que es y ha de ser Europa, reduciendo u ocultando otras acepciones fundamentadas en la variedad de sus rasgos físicos, la heterogeneidad cultural -en todas sus acepciones- o en la espacialización del desarrollo económico o de algunas de las manifestaciones del sistema productivo, por ejemplo. La idea de Europa como ente de naturaleza política es dominante, pero no excluyente de otras acepciones, que también aparecen vivas, dado su uso generalizado -en muchas ocasiones como concepto operativo- o bien por el hecho de constituir conceptos interpretativos del pasado del Viejo Continente o proyectos de futuro sobre lo que ha de ser Europa, más allá -o además- de su contenido político.

A partir del planteamiento señalado se asume que el concepto político de Europa es una de sus acepciones y que, en consecuencia, el mapa político de Europa es uno más de entre otros mapas de Europa, verdaderas representaciones de europas adjetivizadas. Ante este razonamiento surge una nueva pregunta: ¿existe un único mapa de Europa?, de una Europa sin adjetivos. A continuación se exponen argumentos y reflexiones sobre estas cuestiones, con énfasis en la consideración de las acepciones de la palabra Europa, su concepto geográfico y su concepto político, con el propósito de facilitar una mayor comprensión de la evolución del mapa de la Unión Europea, sus límites y sus parámetros actuales.

\section{EUROPA: ESPACIO GEOGRÁFICO Y LÍMITES DEL CONTINENTE}

Suele ser fácil escribir sobre Europa. Ninguna otra parte del Mundo ha sido tan completamente descrita, analizada, medida y representada en los mapas. Pero la individualización de Europa como espacio geográfico resulta difícil -o cuando no controvertida- debido a diversas razones. Europa es un continente por convención (BAYLINA Y PRATS, 2001, 135) y por ello su delimitación está expuesta a múltiples interpretaciones sobre el alcance de su ámbito espacial, y se presenta falta de contundencia. Para dar respuesta a esta cuestión en las 
líneas que siguen se recogen las descripciones que realizan varios geógrafos en obras recientes sobre los límites de Europa como continente y sobre los rasgos básicos que definen Europa.

En una obra reciente (LÓPEZ PALOMEQUE, 2000a, 27) señalábamos que una simple ojeada al globo terrestre pone de manifiesto que lo que entendemos por Europa es una de las grandes partes en las que se divide el Mundo, uno de sus continentes, el apéndice occidental de la masa terrestre más grande de la Tierra, una porción del bloque euroasiático, comprendido entre el Atlántico y los Urales, el océano Glacial Ártico y el Mediterráneo. En esta condición geográfica se fundamenta su doble acepción: pequeño continente y península occidental de Eurasia. Normalmente el encuadre geográfico de los mapas de Europa suele ser el esbozado por el humanista Mercator en su Mapa de Europa del siglo XVI.

De acuerdo con la opción señalada en el punto anterior, los límites tradicionales de Europa como continente son: por el este, la línea de crestas de los Urales y el eje que, en prolongación de éstos, por el río Ural llega al mar Caspio; por el sur, es el Cáucaso -pero, ¿hay que adjudicar a Europa o a Asia ese monte Elbruz, cuyos 5.633 metros de altura destrona los 4.807 metros del Montblanc? ó ¿hay que considerar como límite la cordillera del Gran Cáucaso o del Pequeño Cáucaso, con lo que toda la Caucasia sería Europa?-, el mar Negro y el Mediterráneo con todas sus islas; por el oeste, el océano Atlántico, con varias islas, con Islandia pero no con Groenlandia, con la islas Británicas; por el norte, finalmente, la parte del océano Glacial Ártico que ocupan el archipiélago de Svalbard junto con el Spitzberg, el mar de Barents, la isla de Nueva Zembla y el reborde oeste del mar de Kara. En la malla de meridianos y paralelos, la península europea queda situada entre los $60^{\circ}$ de longitud oriental y los $10^{\circ} \mathrm{de}$ longitud occidental; entre $\operatorname{los} 36^{\circ}$ y $71^{\circ}$ latitud Norte. Casi toda Europa queda, pues, dentro de la zona templada y en una céntrica situación dentro del hemisferio de las tierras emergidas. Europa tiene, como resultado de los límites indicados, una extensión de 10,5 millones de $\mathrm{km} 2$-casi una octava parte del conjunto de las tierras emergidas- $y$ en el que habitan 730 millones de personas, cifra que representa el $12 \%$ de la población mundial, proporción que tiende a disminuir debido al mayor ritmo de crecimiento de la población de los otras grandes regiones del Mundo.

Sin replantearnos los límites usuales del continente interesa hacer mención a los hechos que dan paso a la imprecisión de los mismos. La pequeña Europa no es más que una península de Asia y por ello resulta difícil fijar un límite por el lado del continente asiático (DERRUAU, 1957), y en la concepción de los occidentales, este límite ha variado con frecuencia: en la antigüedad lo hacían llegar hasta el Don; nosotros lo fijamos en los Urales -en opinión de Derruau-, como 
es clásico hacerlo hoy día. De todas maneras Europa no queda mucho mejor definida por los océanos y mares que la rodean, Atlántico y Mediterráneo, que por el Don, el Cáucaso o los Urales. ¿A que continente atribuir Islandia? ¿A Europa o a América?. No siendo poblada más que por escandinavos, decidiremos agregarla a Europa, a pesar de que está más cerca de Groenlandia que de la costa noruega o de la de Escocia. En cuanto al Mediterráneo, constituye un límite natural más cómodo que indiscutible. El norte de África recuerda la península Ibérica por su relieve, y en este sentido el África real empieza cuando se llega al desierto, estando el conjunto Mediterráneo a caballo de los dos mundos (DERRUAU, 1957, 1 y 2). Pero no solamente se detectan estas similitudes en el medio físico sino que el propio Mediterráneo es considerado por algunos autores, más que una línea de separación, un vínculo de unión entre todos los países ribereños de la cuenca (LÓPEZ PALOMEQUE, 2000b). A partir de unas condiciones ecológicas similares ha desarrollado unos modos de vida tradicionales claramente emparentados que exigen un tratamiento de conjunto (FERRÁs, 1990), aunque sin negar esa semejanza otros autores consideran que no pueden ignorarse los contrastes actuales entre ambas orillas, el Mediterráneo septentrional y el Mediterráneo meridional (MÉNDEZ Y MOLINERO, 1998, 69). También las dudas afectan a escala "intracontinental": para unos, Europa se identifica sólo con el área occidental del continente, y por ello Rusia ha visto cuestionada su europeidad, tanto desde dentro como desde fuera. Estas polémicas, por otra parte, han variado constantemente a lo largo de la historia y, en suma, supone una controversia casi constante y no exenta de apasionamiento.

El contorno del continente aparece dibujado por una gran número de penetraciones y fachadas marítimas, de sucesión de penínsulas y golfos, lo cual provoca que se parezca más a una península o a un archipiélago que a un auténtico continente. En definitiva, Europa es un espacio físico muy fragmentado y abierto al mar, que presenta unos límites inciertos y fluctuantes, según BAYLINA Y PRATS $(2001,135)$, que los describe con las siguientes referencias: el Océano Ártico y los archipiélagos de la Tierra de Francisco José, Spirzbergen y Nueva Tierra, así como las regiones más septentrionales de los países nórdicos y de Rusia son el límite norte del continente; el Océano Atlántico y en concreto las islas de Islandia, las Feroe, las Shetland, las Azores, Madeira y las islas Canarias conforman los confines occidentales de Europa; al sur el Mediterráneo y el mar Negro separan Europa de África y Asia; al este, en cambio, los límites son mucho menos definidos. Se ha ido aceptando que los límites orientales se encuentran en el amplio istmo entre el Ártico y el mar Caspio, ocupado por la cordillera de los montes Urales y la cuenca del río Ural. Al sur la barrera montañosa del Cáucaso representa la última frontera con Asia. Esta delimitación, sobre todo hoy día, es muy ficticia y mucho más desde el punto de vista político. La desaparición de la Unión Soviética, el resurgimiento 
de los nacionalismos y la ampliación del número de miembros de la Unión Europa hacen que en el este no se dibuje una línea divisoria clara.

LÓPEZ TRIGAL $(1999,37)$ al abordar la cuestión de la delimitación de Europa señala que es un término geográfico que hace referencia a un continente o más bien a la parte occidental del gran continente de Eurasia y, también, a una unidad regional en el conjunto de unidades del mundo. Si se trata de continente o incluso de subcontinente, su delimitación común va desde el Atlántico Norte, incluyendo Islandia y las Azores, hasta la línea que recorre en el Oriente los montes Urales y el río Ural, en el Sur el Cáucaso, el mar Negro y el Mar Mediterráneo, excluyendo, por tanto a los países caucasianos de la vertiente Sur, a Turquía e islas griegas orientales además de la isla de Chipre. A buen seguro que la delimitación oriental y suroriental no está precisada del todo, tanto en términos geográficos como en términos geopolíticos.

Para reforzar la descripción de los límites del Europa como continente se incorpora la delimitación que hacen BERENTSEN Y DIEM $(2002,3)$ en su obra sobre Europa: en términos de geografía física, las fronteras de Europa vienen definidas por los montes Urales, el río Ural y el mar Caspio, al este; la vertiente septentrional de la cordillera del Cáucaso y los mares Negro y Mediterráneo, al sur; el océano Atlántico al oeste y el océano Ártico al norte. Esta definición fisiográfica es práctica, aunque bastante arbitraria y abre paso a toda una serie de interrogantes, que conducen a hablar de los confusos detalles del mapa de Europa.

La acepción de Europa como continente, como espacio físico, conlleva a utilizar criterios físicos para su delimitación, que como se ha observado en algunos ámbitos son imprecisos. Sin embargo, la geografia fisica, aunque muestra poca contundencia en el oriente europeo, deviene criterio básico delimitador del continente, que adquiere fuerza ante la no coincidencia de los límites de otros conjuntos espaciales (económicos, culturales, políticos) en una región de transición euroasiática y de límites imprecisos.

La compleja realidad territorial de la Europa actual se define por su diversidad cultural característica de la sociedad europea, la convencionalidad de los límites del territorio y la variabilidad de las fronteras a lo largo del tiempo (BAYLINA Y PRATS, 2001). Con todo, Europa y lo europeo tienen un sello inconfundible, una identidad de la que los habitantes del continente son conscientes y los distingue por encima de la heterogeneidad. Los rasgos definidores de Europa como espacio geográfico, que en buena medida lo singularizan y diferencian del resto de las grandes regiones del Mundo y dan personalidad al viejo continente. De manera sintetizada son: 1) variedad y moderación de los rasgos físicos; 2) naturaleza esencialmente "marítima" del "continente"; 3) heteroge- 
neidad cultural, en todas sus acepciones; 4) nivel elevado de desarrollo socioeconómico, con contrastes regionales; 5) división en áreas de estabilidad y áreas de inestabilidad; 6) papel principal o destacado en la historia de la humanidad en los últimos siglos; 7) gran dinamismo de sus componentes y continua transformación de sus estructuras; y 8) permanencia de vínculos e imprecisión de fronteras con las regiones vecinas (LÓPEZ PALOMEQUE, 2000, 37).

\section{EL MAPA POLÍTICO DE EUROPA Y EUROPA COMO PROYECTO POLÍTICO}

\section{La representación cartográfica de la organización política: el papel del Estado y el dinamismo de las fronteras.}

El análisis de las acepciones de Europa permite constatar que Europa como continente constituye un marco espacial y un escenario donde se desarrollan diversos procesos físicos y sociales (culturales, económicos, políticos,..), procesos configuradores de la realidad territorial, diversa y dinámica, de esta región de escala continental. Atendiendo a su geografía física sus límites corresponden con los del continente, como expresión física, como contenedor y como escenario de una dialéctica hombre/medio. Su descripción y explicación permite constatar la existencia de otros conjuntos espaciales (económicos, políticos, deportivos,..), no siempre coincidentes, a veces superpuestos, a veces desbordando el perímetro del continente; y en otras ocasiones dibujando unos conjuntos de inferior extensión.

En esta ocasión interesa centrar la atención en el caso de los conjuntos políticos, en las características de la estructura geopolítica de este continente. A pesar de la importancia de las organizaciones internacionales, Europa, como la mayor parte del mundo, sigue dominada políticamente por los denominados Estados/Nación (BERENTSEN Y DIEM, 2000, 41). El "Estado" es una forma de organización geopolítica, producto en gran medida de los siglos XIX y XX, que se supone gobierna "naciones" -grupos de personas que se identifican con una entidad político-cultural distintiva frecuentemente en base a una etnia común (o que se percibe como tal) y a su establecimiento en un territorio asimismo común, de carácter continuo. Todos los países poseen, además, oficialmente unidades administrativas de carácter regional de importancia variable y, también, con límites dinámicos a través del tiempo.

Los Estados soberanos o Estados/Nación europeos presentan múltiples formas de organización política y, en concreto, diversas "formas de estado". En los primeros años del siglo XXI del total de países que dibujan del mapa político europeo 10 son monarquías, 35 son repúblicas y 3 presentan formas singulares. Los Estados existentes hoy día se han formado en momentos históricos 
diferentes. Así, los Estados de más antigua formación, los creados antes del Congreso de Viena de 1814, son 8: Portugal, España, Francia, Reino Unido, Dinamarca, Suecia, Rusia y Turquía. En sentido contrario, los Estados de formación más reciente, a partir de 1989, son 17 y se han creado como consecuencia del proceso de desintegración de la Unión Soviética, Yugoslavia y Checoslovaquia.

Los Estados soberanos o Estados/Nación europeos presentan, a su vez, múltiples tamaños. Por una parte, Rusia es el sistema territorial más vasto del mundo, con una extensión de 17,1 millones de $\mathrm{km}^{2}$, de los que casi 4 millones de $\mathrm{km}^{2}$ (el 23\%), es territorio situado en el continente europeo. Después de Rusia -y sin considerar a Turquía, que solo tiene el $3 \%$ de sus $780.000 \mathrm{~km}^{2}$ en el continente europeo- los países más grandes son Ucrania $\left(603.000 \mathrm{~km}^{2}\right)$, Francia $\left(547.000 \mathrm{~km}^{2}\right)$, España $\left(504.000 \mathrm{~km}^{2}\right)$, Suecia $\left(449.000 \mathrm{~km}^{2}\right)$, Alemania $\left(356.000 \mathrm{~km}^{2}\right)$, Finlandia $\left(337.000 \mathrm{~km}^{2}\right)$, Noruega $\left(324.000 \mathrm{~km}^{2}\right)$ y Polonia $\left(312.000 \mathrm{~km}^{2}\right)$. En sentido contrario el mapa político de Europa alberga Estados de reducida extensión, son los "microestados", entre los que cabe citar Vaticano, Mónaco, San Marino, Liechtenstein, Malta y Andorra, que en ningún caso superan los $500 \mathrm{~km}^{2}$ de superficie.

Como se sabe, un Estado o una "agrupación de Estados" constituyen un conjunto espacial y, a la vez un concepto geográfico. El Estado es un conjunto geográfico fundamental puesto que el Estado está, ante todo y primordialmente, caracterizado por su territorio. Es un conjunto porque todos sus habitantes están sometidos a las mismas leyes, entienden la misma lengua, pagan los mismos impuestos, ... y recuerdan un pasado común. Este conjunto político y cultural es también, pues, un conjunto espacial cuyos límites precisos y bien conocidos resultan a menudo muy visibles sobre el territorio (NOGUÉ, 1997). En ello se fundamenta, precisamente, la sinergia entre el concepto geográfico y el concepto político de Europa. El moderno Estado nacional constituye hoy la más poderosa de las unidades espaciales del territorio. Y una de las características de los estados radica en el difícil equilibrio que, en el contexto de los intereses internacionales, afecta a la estabilidad- inestabilidad de sus fronteras, al nacimiento de conflictos entre Estados debido a factores diversos (históricos, políticos, geográficos,...).

Los proyectos políticos de Europa necesariamente se dibujan en un mapa, en el que aparecen las líneas divisorias entre Estados, entre unidades políticas supranacionales o entre unidades administrativas de los Estados, es decir modelos de organización territorial del Estado u organización políticaadministrativa del territorio que también han cambiado (MARTí HENNEBERG, 2002). El mapa político revela la correspondencia espacial de la estructura política y de sus límites con respecto a los del continente, a los del concepto 
geográfico. En unos casos, los conjuntos geopolíticos son de escala intracontinental, en otras ocasiones coinciden a grandes rasgos con los límites del continente y a veces constituyen ámbitos que superan las fronteras del Viejo Continente.

El mapa político de Europa representa, pues, la estructura geopolítica de los Estados independientes o soberanos del continente europeo, que han variado en número y forma a través del tiempo. Sin embargo, últimamente se utiliza tanto en el lenguaje político como en el lenguaje común, la expresión "mapa político de Europa" -en ocasiones simplemente del "mapa de Europa"- para referirse al "mapa político de la Unión Europea", lo que supone una simplificación y una referencia reduccionista de los procesos de transformación del "mapa de Europa", en su dimensión histórico/temporal y en su dimensión territorial. Como contrapunto, si se observa el uso institucional de estos términos, se constata como la Comisión Europea, que publica una serie de mapas políticos y temáticos de los quince países miembros, utiliza una denominación precisa y rigurosa en sus productos editoriales. Concretamente, uno de los mapas editados es "El mapa político de la Unión Europa: Estados miembros, regiones y unidades administrativas", que es el que corresponde a la denominación común de "mapa político".

En el primer apartado se ha hecho mención al desplazamiento semántico de la palabra "Europa", a la simplificación y reduccionismo de sus nuevos significados, que en lo político se traduce en el uso de la palabra "Europa" para referirse a la "Unión Europea". Por consiguiente, cuando se habla del "mapa (político) de Europa" en la mayor parte de las veces se trata del "mapa (político) de la Unión Europea". Sin duda, este desplazamiento de significados se refuerza a través del lenguaje y de la información transmitida por los medios de comunicación, donde no es extraño encontrar titulares como ¿Hasta donde llega Europa?, Los límites de Europa, ¿Dónde acaba Europa?, ¿Dónde está el Este europeo?, y otras similares que ilustran los argumentos expuestos.

\section{El mapa político de Europa: un mapa de geometría variable}

Se ha escrito a menudo que Europa es un concepto histórico y geopolítico de "geometría variable" y una noción geográfica sin fronteras precisas con Asia. La imprecisión de los límites del espacio físico se proyecta, a su vez, sobre la estructura espacial de los organismos políticos, sobre el mapa político de Europa. Esta circunstancia confiere una alto grado de arbitrariedad a los argumentos utilizados para definir lo que es Europa y lo que no es Europa, y los propios límites de una Europa política. Históricamente se ha caracterizado por una fragmentación muy acusada y por cambios frecuentes de su división política: Europa es el espacio resultante de la confluencia de muchos pueblos, y 
su definición como comunidad humana diferenciada ha sido históricamente muy difícil de establecer.

La geopolítica europea tiene diversas lecturas, de las que destacan dos aparentemente contrapuestas y superpuestas en tiempo y espacio:

a) Europa como yuxtaposición de estados nacionales antiguos y nuevos, y

b) Europa como reencuentro de un espacio y de un proyecto.

En cuanto al mapa político de Europa, el Viejo Continente es a principios del siglo XXI un conjunto territorial compuesto por casi cincuenta estados antiguos o recientes, y más de cincuenta naciones más o menos reafirmadas, con vocación o aspiración nacional. En la actualidad, aceptando un criterio delimitador amplio, el mapa político de Europa está formada por un total de cuarenta y ocho estados soberanos, contando con Turquía y Chipre y también con los tres estados del Cáucaso, la mayoría de ellos de dimensiones reducidas, si se exceptúa Rusia (BAYLINA Y PRATS, 2001, 136).

La historia revela una evolución contemporánea del mapa político de Europa con numerosos cambios, de gran alcance y trascendencia, hecho que puede sorprender ante la idea generalizada de un continente estable en sus fronteras internas y de una estructura política consolidada como hechos propios de un continente de avanzada civilización. X. BATALLA, experto articulista sobre temas de historia y política europea, recoge en un texto reciente las fechas clave y los hitos básicos en la evolución de la estructura política europea, de los cambios del mapa político de Europa (La Vanguardia, 24 de noviembre de 2002):

- 1818. El Congreso de Viena, después de la derrota de Napoleón, redibujó el mapa europeo. Gran Bretaña, Prusia, Austria, Rusia y Francia integraron el concierto Europeo, alianza que procuró la paz en 1914.

- 1885. Con la unificación alemana, en 1871, surgió un gigante en Europa central. Cuatro decenios más tarde los imperios alemán, austro-húngaro y otomano se aliarán en la guerra de 1914.

- 1924. Una vez terminada la Primera Guerra Mundial, el mapa de Europa volvió a cambiar: Los latifundios multiétnicos imperiales estallaron, con la excepción del soviético, para dar paso a minifundismos nacionales.

- 1947. La Guerra Fría (1949-1989) dividió el continente europeo en dos mitades: la occidental, bajo el paraguas de la OTAN, y la oriental, integrada en el Pacto de Varsovia. 
- 1989. Inicio del desmoronamiento de la Unión Soviética y nacimiento de nuevos estados soberanos. El mapa político de los Estados europeos vuelve a sufrir grandes cambios.

A escala planetaria, Europa es el único continente donde continúan los procesos de formación nacional y de acceso a la independencia de estados nuevos, debido a la disolución de tres federaciones formadas en 1919 -Yugoslavia, Checoslovaquia- o después de la desaparición política del zarismo (la Unión Soviética). Europa ha vivido a lo largo del siglo XX importantes cambios de sus fronteras políticas (REBAGLIATO, 1994a y 1994b), que han derivado en las últimas décadas en un complejo proceso de construcción, deconstrucción y reconstrucción (VICENTE, 1993). Pero, además del mapa de los Estados, el continente europeo es una malla densa de instituciones políticas supraestatales, destacando el proyecto de integración europea de la Unión Europea (FOUCHER, 1994).

Los cambios políticos ocurridos a partir de 1990 han conducido a la mudanza del mapa de los Estados de Europa, que hasta entonces era intangible como consecuencia del tratado de Yalta de 1945. El mapa político de Europa había estado mucho tiempo sin ser alterado, si se compara este último período con los anteriores a lo largo de los dos últimos siglos, pues no se caracteriza por ser un mapa consolidado a lo largo de períodos dilatados, ya que más bien en cuanto transcurren cortos períodos de décadas se suceden diferentes etapas en la organización y delimitación de los Estados contemporáneos de Europa, que han pasado por procesos bien de integración o bien de segregación, según las tendencias existentes en una determinada dirección en cada época (LÓPEZ TRIGAL, 1999, 371).

En la última década Europa ha vivido un proceso de reestructuración geopolítica y geoeconómica -aún inacabado-, no sólo debido a la formación de la Unión Europea y las muchas variaciones en el mapa regional de los Estados comunitarios, sino a partir de la descomposición principalmente del bloque excomunista, una vez producida la eclosión de la económica soviética y la recomposición del espacio post-soviético. Sin embargo, y desde otro prisma, parece que con el final de la guerra fría y fruto de esta recomposición, Europa se ha reencontrado. Se puede afirmar que Europa, la realidad geográfica identificada con esta entidad cultural, espacial y política, recupera regiones y países largamente divididos. Pero las verdaderas mutaciones en que este proceso se materializa van más allá (PLAZA, 1997, 269).

En efecto, en Europa se ha venido enfrentando el proceso de integración generalizada entre los años 1945 y 1990, tanto en occidente (Unión Europea) como en el oriente (Países del Pacto de Varsovia) hasta que en los últimos años se vuelve a un proceso de fragmentación en Europa oriental (SÁNCHEZ SÁNCHEZ, 
1995), mientras que sale fortalecida la tendencia integradora de la Unión Europea, estando a la espera de entrar en ésta buena parte de los países eurorientales, incluyendo Turquía y Chipre, por entender que son "parte de Europa" (LÓPEZ TRIGAL, 1999, 373).

Además de la lectura geopolítica que identifica Europa como yuxtaposición de estados nacionales antiguos y nuevos y, por otra parte, como reencuentro de un espacio y de un proyecto, la dualidad europea se lee también sobre dos registros de tendencias opuestas en el tiempo y en el espacio:

1. por una parte, el Viejo Continente parece pasar por un movimiento contradictorio, ya que su Occidente desarrolla un proyecto de integración política, mientras que su Oriente se fragmenta de manera a veces violenta, y

2. por otra parte, la existencia de naciones sin Estado, los debates sobre la Unión Europea y las inercias de la recomposición del espacio postsoviético muestran la vitalidad y el resurgir de las nacionalismos, que no se limitan solo a la antigua Europa del este sino que es propio de todo el continente.

\section{Europa como proyecto político: antecedentes}

Europa como proyecto político, como idea que asocia en "una sola entidad política" a todo el continente, no es un hecho nuevo y en su evolución destacan las ideas panaeuropeas los siglos XIX y XX. Lo nuevo hoy radica tanto en el vigor del proyecto -que surge y ocupa un espacio occidental de Europa- como en la realidad evidente de la existencia de la Unión Europea, lo que permite entender «Europa» como reencuentro de un espacio y de un proyecto. En este proceso la palabra «Europa» se refiere en realidad a la construcción voluntaria de una asociación duradera entre seis, nueve, doce, quince,... Estados, después de la firma de los distintos tratados que han ratificado dicha voluntad. Europa es el único continente que dispone de un proyecto orientado a edificar un sistema geopolítico multinacional y multiestatal, autónomo, influyente a escala mundial y original, sin ser de naturaleza imperial ni estar sujeto a un estado dominante, puesto que se rige por un sistema de relaciones contractuales tejido entre sus miembros. Es por ello por lo que la mayoría de los Estados europeos se han fijado como objetivo estratégico adherirse a esta comunidad. Esto confirma que la actual UE se ha convertido en el corazón político, así como económico e institucional, del continente.

La idea y el camino hacia una Europa unida no es reciente en la historia del Viejo Continente. Se podría decir que Europa es un continente que no ha estado nunca unido, a pesar de los intentos que se han dado para conseguirlo, que siempre han sido violentos y abocados al fracaso. Al margen de los dos "imperios" (Carlomagno y Napoleón), la idea de "un" poder político en Europa, 
que asegurase la gestión de un espacio concebido de forma tan confusa, sólo podía nacer tardíamente.

En este sentido, cabe señalar dos proyectos de arquitectura europea: la Confederación de Georges Podiebrad (1464), Rey de Bohemia, y el Gran Proyecto del Duque de Sully (1638 a 1662). A mediados del siglo XVII, Sully retirado de los asuntos públicos, imaginaba en su Sages et Royales Économiques un Consejo de Europa que dominase once monarquías y cuatro repúblicas, pero excluyendo de ella a Rusia. Más tarde, Saint-Simon, en 1814, quería "reorganizar la sociedad europea"; Víctor Hugo, en 1851, hablaba de los Estados Unidos de Europa. No fue hasta el siglo XX cuando se pudo intentar una acción en pro de una "Panaeuropa". En este sentido, el movimiento paneuropeo preconizado por el conde austriaco Richard Coudenhove-Kalergi (1894-1972) puede considerarse el primer movimiento que proponía una línea integradora europea, al promover la creación de los estados unidos de Europa con el fin de establecer un sistema de seguridad europeo.

Sólo en las últimas décadas del siglo XX las instituciones han asumido el calificativo de "europeo" para realidades que, por otra parte, sólo lo eran de forma incompleta. De igual manera, los proyectos y acciones tendentes a superar la diversidad continental ofrecen múltiples variantes. Fenómeno esencialmente ideológico, unas veces ha sido fruto del pensamiento de pacifistas utópicos, otras ha respondido a los intereses particulares de los Estados y en ocasiones ha servido para alumbrar proyectos muy pragmáticos y concretos. Los historiadores señalan que la Segunda Guerra Mundial fue el detonante que volvió a revitalizar la necesidad de una "unión europea". Lo cierto es que a partir de la postguerra, y como relación causa/efecto del nuevo escenario geopolítico, empezaron a crearse diversos organismos y asociaciones supranacionales de naturaleza política o económica, que sin duda fueron el inicio de los procesos de integración en todos los órdenes y de la construcción europea que hoy tiene mucho de realidad.

En este sentido, cabe recordar el significado del Plan Marshall (1947); la creación en 1949 del Consejo de Europa (organismo confederal que tiene como objetivo actuar en temas culturales, sociales y medioambientales, y que no tiene competencias en los ámbitos económicos y de defensa); la firma del Pacto Atlántico (12 estados) en 1949; la creación de la Organización del Tratado del Atlántico Norte (OTAN) en 1959 (la estructura político y militar permanente con que se dotó el Pacto Atlántico); la creación del Benelux en 1948; la formación de la Comunidad Europea del Carbón y del Acero (CECA) y la firma en 1957 del Tratado de Roma por el que se creó la Comunidad Económica Europea (CEE), cuyo objetivo principal fue crear un gran mercado común entre países miembros. 


\section{La Unión Europea como proyecto político continental}

a) Concepto y formación

Lo que actualmente se conoce como «Unión Europea», instituida como tal desde el Tratado de Maastricht o Tratado de la Unión Europea, firmado el 7 de febrero de1992 y que entró en vigor el 1 de noviembre de 1993, es la evolución temporal a través de un largo proceso iniciado en los años cincuenta del original Mercado Común Europeo. Desde entonces ha ido derivando paulatinamente hacia una Comunidad más integrada, de intereses convergentes y con un gradual incremento de su peso sociopolítico, pasando por las distintas formas como ha sido concebido: Comunidad Económica Europea (CEE), Comunidad Europea (CE) y Unión Europea (UE) (PLAZA, 2000c, 543). Es a mitad de siglo $\mathrm{XX}$ cuando nacen las dos corrientes de pensamiento que han dado cuerpo al proceso de integración comunitaria: federalista y funcionalista. Ambos confluyen hoy en el convencimiento de que debe existir un poder europeo que se asiente en unas instituciones democráticas e independientes, con capacidad para regir aquellos sectores en los que la acción común resulta más eficaz que la de los Estados individualmente: mercado interior, moneda, cohesión económica y social, política exterior y seguridad.

La UE se define, ante todo, como una forma concreta y un proceso determinado de integración, que es de naturaleza económica y de ámbito supranacional e internacional, pues reúne a países muy diversos, pese a que se constituyera a partir de un núcleo de economías más desarrolladas que querían encauzar la consecución de una paz estable, recuperar su capacidad productiva así como la de Europa en general y reintegrar al continente su poderío y potencial económico en el panorama mundial.

Ello se traduce, en la práctica, en la configuración de un sistema y un espacio económico comunes, dentro del modelo capitalista y de mercado, que agrupan y reúnen hoy los recursos y territorios de quince países miembros -algo más de tres millones de $\mathrm{km}^{2}$ extendidos entre el Atlántico y el Danubio medio y desde latitudes superiores al Círculo Polar Ártico hasta la cuenca mediterránea (PLAZA, 2002, 544).

Pero junto a este reforzamiento socioeconómico el ámbito o carácter supranacional significa que esta integración se apoya en órganos soberanos de gobierno y gestión en los que hay miembros de los distintos países que la constituyen pero que actúan para todo el conjunto, atendiendo a una comunidad de intereses, aunque sabiendo interpretar también las situaciones particulares. Supone también la cesión, por cada país, de parte de su soberanía a unas instituciones y autoridades comunes. 
En definitiva, todo este proceso traduce la voluntad de un proyecto de crear una Europa Unida, que es entendida con una doble condición: a) como un espacio geográfico progresivamente más y mejor integrado, común, sin fronteras, abierto; b) como una realidad económica, política y territorial, tal como lo demuestra su desarrollo paulatino, tanto desde la perspectiva territorial -con la progresiva ampliación de sus límites acogiendo a un mayor número de miembros- como en lo político e institucional (diversos Tratados constitutivos y sucesivas redefiniciones y revisiones de los mismos; paulatino perfeccionamiento del sistema institucional sobre el que se apoya y de sus condiciones de funcionamiento; etc.).

\section{b) Orígenes, evolución institucional y evolución territorial.}

El paso en los últimos cincuenta años de la originaria Comunidad Económica Europea a la actual Unión Europea es fruto de una evolución institucional y territorial caracterizada por situaciones de encuentros y desencuentros y marcada por ritmos contrastados.

Los Tratados de Roma, que se firmaron en la capital italiana el 25 de marzo de 1957 por Francia, la República Federal Alemana, Italia, Bélgica, Holanda y Luxemburgo, tienen que considerarse tanto un instrumento para la creación de entes supranacionales con personalidad propia (la Comunidad Económica Europea-CEE- y la Comunidad Europea de la Energía Atómica-EURATOM), como una respuesta original a las inercias existentes en los Estados de Europa Occidental respecto a su soberanía. Los Tratados de Roma se limitaban al sector de la economía, ya que a los Estados miembros les parecía el campo más razonable en el que podían renunciar a su soberanía sin renunciar a su esencia nacional. Las sedes de las Comunidades se fijaron en Bruselas y se inició su funcionamiento el 1 de enero de 1958 (BRU-DIR-, 1999, 213).

El objetivo principal que se pretendía con la fundación de la CEE era crear un gran "mercado común" entre los países miembros para facilitar la libre circulación de mercancías, personas, capitales y servicios, y conseguir progresivamente una unidad política (BAYLINA Y PRATS, 2001, 141). El objetivo explícito de los Tratados era constituir un mercado único, tal como se ha señalado, pero indiscutiblemente su finalidad, en el espíritu de quienes lo forjaron, era político. Sus resultados institucionales, en definitiva, deben se considerados más que como un producto final como una fase del proceso de construcción europea (BRU -dir-, 1999, 213).

La evolución institucional no puede disociarse de la evolución territorial y viceversa. En esta ocasión, al tratar estos temas se hace mención solamente a los hechos más destacados que ilustran el paso de la CEE a la UE. En cuanto a la 
evolución territorial señalar que la CEE como organismo supranacional ha vivido cinco ampliaciones, que han supuesto un crecimiento superficial y un ensanchamiento geográfico destacado, tanto hacia el sur (países mediterráneos) como hacia el norte (países atlánticos y nórdicos) o hacia el este (países de la Europa central y oriental - PECO's). Cada una de las fases de ampliación ha comportado largos procesos de negociaciones y toma de decisiones, a partir de problemáticas de partida $\mathrm{y}$, a su vez, creándose nuevos problemas con cada ampliación. En definitiva, cada ampliación ha tenido, en cada caso, unos significados políticos, territoriales y económicos distintos.

La primera ampliación data de 1973, cuando ingresan en la CEE Irlanda, Dinamarca y el Reino Unido. A destacar, por una parte, que el Reino Unido rechazó participar en la formación inicial tanto de la CECA como de la CEE y, por otra parte, que estos países junto a Noruega solicitaron su integración en 1961. Noruega no ingresó en 1973 porque el referéndum que celebró el 22 de septiembre 1972 fue negativo.

La segunda ampliación en 1981 supuso la adhesión de Grecia y la tercera en 1986 el ingreso de los dos países ibéricos: España y Portugal. Cabe destacar que estas dos ampliaciones de los años ochenta supusieron la entrada a la CEE de tres países mediterráneos (ampliación hacia el sur), con todo lo que representaba en términos cualitativos (estructura productiva, nivel de desarrollo, ...), siendo países que además estrenaban democracia después de un periodo de régimen dictatorial (BAYLINA Y PRATS, 2001, 142). Entre la segunda y la tercera ampliación tuvo lugar un "crecimiento" de la UE que en términos jurídicos e institucionales no se califica como tal, a pesar de su significado tanto en términos cuantitativos como cualitativos. Se trata de la "incorporación" en 1990 de la antigua Alemania Democrática a través de la reunificación de Alemania.

La cuarta ampliación se produjo en 1995 y supuso un ensanchamiento de la UE hacia el centro y norte de Europa con la incorporación de Austria, Finlandia y Suecia, países miembros a su vez de la AELC. En esta ampliación también era candidato Noruega, pero por segunda vez en su historia el pueblos noruego mediante referéndum rechazó ( $52,2 \%$ en contra y $47,8 \%$ a favor) su ingreso en la UE. El resultado de la cuarta ampliación dio paso a la UE de 15 países, con una población de 378,5 millones de habitantes y una superficie geográfica de 2,75 millones de $\mathrm{km}^{2}$.

La quinta ampliación es fundamentalmente la ampliación hacia el este del Viejo Continente y contempla la incorporación de 10 nuevos países principalmente de Europa central y oriental (PECO's), prevista para el 2004, 
con lo que la UE pasará de 15 a 25 países miembros, sumando una población de 444,4 millones de habitantes y una extensión de 3,49 millones de $\mathrm{km}^{2}$.

En casi 50 años se ha pasado de una Comunidad Europea de seis países con apenas 180 millones de habitantes (un tercio de la población del continente) y una extensión superficial de 1,24 millones de $\mathrm{km}^{2}$ (el 11\% del continente) a una Unión Europea de 25 países con más de 444 millones de habitantes (el $61 \%$ del total de la población europea) y una superficie territorial de 3,48 millones de $\mathrm{km}^{2}$, que supone un tercio de la extensión total del Viejo Continente.

En cuanto a la evolución institucional, además de las referencias señaladas en torno a los diversos tratados fundacionales y de reformas, cabe indicar que a lo largo de sus casi cincuenta años la CEE-CE-UE paralelamente a su ampliación geográfica ha ido modificando y adaptando sus acciones, profundizando sus objetivos e institucionalizando sus estructuras. En concreto, en este largo y complejo proceso destacan como referencias ineludibles la implantación de la "unión aduanera" y de la emblemática política agraria común (PAC) a partir de 1968; la ampliación a partir de los años setenta de las políticas comunes y el diseño de las acciones de ayuda y cooperación con antiguas colonias y territorios de ultramar de países miembros; la creación en 1974 del Consejo Europeo; la primera elección por sufragio universal al Parlamento en 1979 y, en este mismo año, la implantación del Sistema Monetario Europeo (SME).

A partir de los ochenta tienen lugar cambios constitutivos en los tratados fundacionales que recogen de manera explícita la profundización de los objetivos y el proceso de adecuación institucional y política las futuras ampliaciones. El año 1985 la Comisión Europea presidida por Jacques Delors presentó en el Parlamento Europeo las medidas para conseguir llegar a un mercado interno unificado. Se trata del Acata Única Europea vigente desde 1987. Este acuerdo preparó el terreno para un nuevo tratado, que amplió substancialmente el proyecto de 1957, y que dio paso a la Unión Europea. Este nuevo tratado recibió el nombre de Tratado de la Unión Europea, que se firmó en Maastricht en 1992 y entró en vigor en 1993 (BAYLINA Y PRATS, 2001,143).

El Tratado de la Unión Europea (TUE) o Tratado de Maastricht implicó el fortalecimiento y profundización de la Comunidad Europea. Su objetivo fundamental contempla el llevar a cabo la unión económica y monetaria, como paso previo a la unión política. Entre las novedades más destacadas del Tratado de Maastricht figura la creación de la Unión Monetaria Europea (UEM), estructurada en tres fases y que culminó en el año 2002 con la implantación de la moneda europea, el "euro", a todos los efectos como única moneda del Unión, perdiendo valor de curso legal las monedas de los países miembros. 
En 1995 la Comisión Europea se fijó alcanzar dos objetivos: fortalecer la Unión y preparar la ampliación. Estos objetivos se explicitaron en el Tratado de Amsterdam de 1997, que representó una nueva "constitución" para mejorar el funcionamiento de la UE, y que dio paso una estrategia global formulada como "Agenda 2000", con tres retos principales: 1) reformar y fortalecer las políticas comunitarias con el fin de adaptarlas a las nuevas realidades socioeconómicas y a las nuevas ampliaciones; 2) negociar la ampliación y preparar a los países candidatos, y 3) determinar la financiación de la ampliación. En 1998 empezaron las negociaciones con los países candidatos a la adhesión, a unos ritmos distintos al contemplarse al menos dos etapas tras el necesario cumplimiento por parte de los candidatos de los criterios de Copenhague adaptados en el Consejo Europeo celebrado en 1993. Los países candidatos formaban una amplia lista, para esas dos etapas y para fechas posteriores: Hungría, Polonia, Estonia, República Checa, Eslovenia, Chipre, Malta, Bulgaria, Rumania, Letonia, Lituania, Eslovenia y Turquía, que solicitó su adhesión en 1987. En este marco el escenario futuro se dibujaba con una posible Unión Europea de 25 ó 30 países.

c) La refundación institucional y la expansión territorial de la Unión Europea.

En los últimos años la construcción de la Unión Europea, de Europa como proyecto político, comprende tanto un proceso de naturaleza institucional como de naturaleza territorial, lo que supone un "doble salto" -como lo califica C. Nadal en La Vanguardia (15/12/02)-, al coincidir los desafíos cuantitativos de la ampliación con la voluntad cualitativa de dotarse de una Constitución supranacional. El proceso de integración europea se orienta, pues, en dos direcciones y por eso se afirma que el presente y el futuro de Europa se forja en dos frentes:

1) el frente de la ampliación territorial, es decir la adhesión de nuevos miembros a la Unión Europea. Es un proceso que, finalmente, se manifiesta en mapas, en un "nuevo" mapa que se ensancha hacia el este. La ampliación del número de miembros comporta el incremento de su superficie geográfica, de su población y de su poder económico; en definitiva, la extensión geográfica y el ensanchamiento del mapa político de la UE.

2) el frente de la profundización institucional, con la reforma de sus estructuras y la búsqueda de nuevos objetivos que, finalmente, se manifiesta en las leyes que fundamentan la asignación de competencias entre las instituciones supranacionales y los Estados miembros (sin olvidar los niveles regional y local) y, por otra parte, el reparto del poder de cada Estado miembro en la toma de decisiones y en el sistema de votaciones. Hoy día el horizonte de 
este marco legal básico es la Constitución supranacional de la Unión Europea, en pleno debate en 2003.

El 1 de enero de 2004 concluirá, con la entrada en vigor de la integración de 10 nuevos países, la quinta ampliación de la Unión Europea, la ampliación hacia el este europeo. El proceso se inició prácticamente como causa/efecto del nuevo escenario político que dibujó el desmoronamiento de la Unión Soviética y de los intereses y aspiraciones de los antiguos estados comunistas, de los cambios del Este político. Institucionalmente un referente ineludible es el Consejo Europeo de Copenhague de 1993, que señaló los requisitos necesarios para la adhesión, previa a toda ampliación: 1) estabilidad democrática e institucional; 2) una economía de mercado que permita afrontar las presiones de la competencia en el mercado interior; 3) capacidad de asumir los derechos y obligaciones derivados del acuerdo comunitario y de la aceptación a todos sus objetivos y los de la UEM; y 4) capacidad de admitir nuevos miembros sin que se resienta la dinámica de la integración (BRU -dir-, 2000, 30).

El Consejo Europeo celebrado el 13 de diciembre de 2002, en el marco de la Cumbre de Copenhague, acordó la quinta ampliación de la UE con el ingreso de 10 nuevos países que formarán parte de la nueva Europa: Polonia, Hungría, República Checa, Eslovaquia, Eslovenia, Lituania, Letonia, Estonia, Chipre y Malta. En principio, la adhesión de otros dos países candidatos, Bulgaria y Rumania, se producirá en 2007, siempre que alcancen a tiempo los niveles de preparación necesarios, mientras que con el decimotercer aspirante, Turquía, en 2005 se iniciaran negociaciones para su integración.

Con la declaración de Copenhague sobre "Una sola Europa" se han sentado las bases para superar divisiones y antagonismos seculares. Las más recientes son la guerra fría, pero hay otras que se cuentan por siglos. En la UE ampliada de 2004 y el proceso de nuevas incorporaciones en la actual década faltan los Balcanes que sin duda tendrán su futuro político en la Europa unida, e incluso la declaración de Copenhague ya contempla también relaciones especiales con Rusia, Ucrania, Bielorrusia y Modalvia. Sin duda, un hito histórico de la realidad política del continente europeo.

El proceso de refundación institucional y de expansión territorial de la UE es complejo, rico en matices y dinámico, y por eso inacabado. Además de las características señaladas merecen destacarse, otros rasgos que ilustran el grado de transformación y la trascendencia que representan los avances de los últimos años: 
Cuadro 1. Evolución de los estados miembros de la Unión Europea.

\begin{tabular}{|c|c|c|c|}
\hline & Estados miembros & $\begin{array}{r}\text { Población* } \\
\text { (Millones habs.) }\end{array}$ & $\begin{array}{r}\text { Superficie } \\
\left(\mathrm{Miles} \mathrm{km}^{2}\right)\end{array}$ \\
\hline \multirow{7}{*}{$\begin{array}{l}\text { Tratado de Roma (Ratifi- } \\
\text { cado en } 1957 \text { y en Vigor el } \\
01-01-1958 \text { ) }\end{array}$} & Alemania & 82,2 & 356,7 \\
\hline & Bélgica & 10,3 & 30,5 \\
\hline & Francia & 59,2 & 547,0 \\
\hline & Holanda & 16,0 & 40,8 \\
\hline & Italia & 57,7 & 301,2 \\
\hline & Luxemburgo & 0,5 & 2,5 \\
\hline & Total & 222,5 & $1.242,7$ \\
\hline \multirow[t]{4}{*}{ Primera ampliación (1973) } & Dinamarca & 5,4 & 43,1 \\
\hline & Irlanda & 3,8 & 70,2 \\
\hline & Reino Unido & 59,9 & 244,0 \\
\hline & Total & 69,1 & 357,3 \\
\hline \multirow[t]{2}{*}{ Segunda ampliación (1981) } & Grecia & 10,6 & 131,9 \\
\hline & Total & 10,6 & 131,9 \\
\hline \multirow[t]{3}{*}{ Tercera ampliación (1986) } & España & 39,5 & 504,8 \\
\hline & Portugal & 10,2 & 92,0 \\
\hline & Total & 49,7 & 596,8 \\
\hline \multirow[t]{4}{*}{ Cuarta ampliación (1995) } & Austria & 8,1 & 83,8 \\
\hline & Finlandia & 5,2 & 337,0 \\
\hline & Suecia & 8,8 & \\
\hline & Total & 22,1 & 420,8 \\
\hline \multirow[t]{11}{*}{ Quinta ampliación (2004) } & Chipre & 0,7 & 9,2 \\
\hline & Eslovaquia & 5,4 & 49,0 \\
\hline & Eslovenia & 2,0 & 20,5 \\
\hline & Estonia & 1,4 & 45,1 \\
\hline & Hungría & 10,2 & 93,0 \\
\hline & Letonia & 2,3 & 64,5 \\
\hline & Lituania & 3,5 & 65,2 \\
\hline & Malta & 0,4 & 0,3 \\
\hline & Polonia & 38,7 & 312,7 \\
\hline & República Checa & 10,3 & 79,0 \\
\hline & Total & 74,9 & 738,5 \\
\hline UNION EUROPEA 2004 & 25 países & 444,4 & $3.488,0$ \\
\hline \multirow[t]{3}{*}{ Sexta ampliación (2007) } & Bulgaria & 8,1 & 110,9 \\
\hline & Rumania & 22,4 & 237,5 \\
\hline & Total & 30,5 & 348,4 \\
\hline EUROPA & 48 países & 730,0 & $10.500,0$ \\
\hline
\end{tabular}

* Las cifras de población corresponden el año 2000 ó, en cada caso, al censo más próximo a esta fecha. Se ha optado por los datos del 2000 y no por los correspondientes al año de cada ampliación con el fin de poder comparar las cifras en la situación actual.

FuENTE: Elaboración a partir de BRU-dir- (1999), PLAZA (2000c) y LÓPEZ PALOMEQUE (2000). 
-- La quinta ampliación es la mayor desde su creación, y aporta 75 millones de habitantes y $738 \mathrm{~km}^{2}$. Esta ampliación supone una expansión de la UE hacia el antiguo Este político y hacia la Europa central y oriental, superando el ámbito regional inicial, la Europa occidental. La Unión Europea, el proyecto político más innovador y ambicioso de la historia, ha extendido su influencia democratizadora y estabilizadora hasta las fronteras de Rusia y Ucrania. Es una apuesta histórica de unificación del continente que convertirá a la UE en el "tercer sistema político más poblado del mundo".

-- Los acuerdos de la Cumbre de Copenhague de 2003, el nacimiento de la Europa de los 25 trece años después de la caída del muro de Berlín, suponen el fin a la división política de Europa en dos bloques. Se han sentado las bases para superar divisiones y antagonismos seculares. En Copenhague se han enterrado los Acuerdos de Yalta de 1945, por los que se formalizó la división en dos bloques, Oeste y Este, quedando después de la Segunda Guerra Mundial la mitad de Europa bajo control de la Unión Soviética. La futura adhesión de Turquía, un país musulmán con más población que Francia, Italia o el Reino Unido, extenderá las fronteras de la UE hasta el Cáucaso y Oriente Próximo.

-- El proceso de "profundización" supone la "refundación institucional" de la UE, con la probable aprobación en 2003 ó 2004 de la primera Constitución en casi medio siglo de historia de la UE. Se espera, pues, que el año 2004 sea el de la "refundación europea". La Constitución redactada por la Convención Europea no consiguió, no obstante, el consenso dado el desacuerdo en algunos temas estructurales, entre los que destacan dos cuestiones: a) la relación entre Constitución y religión, en concreto entre los defensores y los detractores de que conste la herencia judeocristiana de la mayoría de los países miembros y que sea considerada como una condición de pertenencia. En este sentido, y como contrapunto, es oportuno señalar que la futura ampliación a Turquía, además de favorecer el desarrollo de un islamismo democrático en ese país y en las comunidades islámicas que existen en nuestros países, tendrá una ventaja adicional para todos los europeos: evitar que la Unión Europea acabe siendo una organización sólo para cristianos, como algunos pretenden; y b) el reparto de poder entre los Estados miembros de la UE y la participación en el sistema de votaciones en los procesos de toma de decisiones. No obstante, ante estas dificultades ha de recordarse que la construcción política de Europa ha avanzado a golpe de crisis.

-- La quinta ampliación creará una Europa más fuerte y estable 
económicamente y con mayor poder político en el concierto mundial. Ampliada a veinticinco países, la Unión Europea será el mayor bloque comercial del mundo y constituirá un mercado único de 500 millones de ciudadanos. Se desea y se prevé que en los nuevos Estados miembros las perspectivas de crecimiento económico aumenten y se garanticen las libertades básicas y los derechos fundamentales. Los Estados miembros actuales se beneficiarán de esta nueva prosperidad, pero la principal ventaja para todos es la expansión general, a través de todo el continente europeo, de la paz y la seguridad a largo plazo. En Europa Central y Oriental, los resultados ya empiezan a ser tangibles: configuración de democracias estables, reconocimiento de los derechos de las minorías e índices elevados de crecimiento económico.

\section{A MODO DE BALANCE Y CONCLUSIONES: UN PROCESO INACABADO Y UN MAPA EN CONSTRUCCIÓN}

Abordar el tema del "nuevo mapa de Europa" supone un ejercicio de geografía continental, un análisis de procesos territoriales y geopolíticos sobre la evolución de las estructuras que conducen a la mudanza tanto del mapa geopolítico de los Estados europeos como de las organizaciones supranacionales europeas.

La palabra Europa ha tenido diversas acepciones a lo largo del tiempo. La geografía contemporánea define y reafirma a Europa como concepto geográfico, un espacio físico y a la vez social, como un territorio fruto de una dialéctica histórica y actual del medio físico y de la sociedad humana. Europa como continente deviene concepto locacional y operativo para la descripción y la explicación de la Tierra, de una de sus partes, del "Viejo Continente" en concreto. La idea de Europa continente -a pesar de la falta de consenso y del debate sobre sus límites y extensión- aparece hoy, a principios de siglo y de milenio, como una acepción tradicional y un convencionalismo vigente para la Geografía y para el conjunto de la sociedad, aceptado y de uso generalizado, sí bien no exento de contradicciones. Y como tal convencionalismo tiene, asimismo, un significado cultural, por cuanto forma parte de unos conceptos o categorías analíticas con los que la comunidad de geógrafos y toda la sociedad se dota para avanzar en el conocimiento del mundo y en la formación de sus habitantes. Europa es concepto geográfico, fundamentado en la condición del continente, pero también -o sobre todo- por la condición de su "contenido", entendiendo el territorio europeo no solo como una realidad física (uno de los continentes), sino como una realidad social que conduce a hablar de lo europeo y la europeidad y de la percepción social de dicha realidad (JORDAN, 1996; CASTRO, 2001). 
Al concepto geográfico de Europa se suman hoy, más que en ningún otro momento histórico, diversas acepciones de esta "palabra". El debate se centra tanto en el Viejo Continente y en el proceso de construcción política europea como en la misma idea de Europa (UNWIN, 1998, 5); e incluso en este sentido se afirma que Europa es una idea polémica y apasionada (GUTIÉRREZ, 1987, 6). Idea e ideas para cuya transmisión se utilizan diversos lenguajes y en la que los medios de comunicación desempeñan un destacado papel. Un ejemplo de la relevancia social del tema y de su presencia en los medios de comunicación es la incorporación de los debates sobre el proceso de integración política en las viñetas que diariamente publica la prensa escrita (por ejemplo las FIGURAS 1 y 2), mapas dibujados de una geografía subjetiva que en clave de metáfora transmite mensajes sobre proyectos de construcción europea, sus realidades y sus percepciones. En este marco destaca la vigencia y la fortaleza de dos acepciones sobre el "Viejo Continente", conceptos que son más sinérgicos que opuestos:

a) El concepto geográfico de Europa, cuya fortaleza se fundamenta tanto en la importancia formativa que tiene la Geografia, en cuyo proceso de enseñanza se reproduce el concepto "tradicional", como en el nivel de aceptación y consolidación que ha adquirido dicho concepto debido a su uso generalizado, operativo y cultural, en distintos ámbitos de la sociedad. En muchas ocasiones, y en lo cotidiano, la idea de "Europa" no aparece formalizada conceptualmente, pero en cambio es aceptada y utilizada explícita o implícitamente como espacio de referencia, como ámbito operativo de organización.

b) El concepto geopolítico de Europa, cuya fortaleza se fundamenta en el papel decisivo que desempeña el Estado en la configuración y articulación del territorio y en el gran dinamismo que en los últimos años ha adquirido el proyecto de construcción política de Europa.

La diversidad de ideas sobre Europa, la vigencia de su concepto geográfico y la sinergia del mismo con otras acepciones, destacando el concepto geopolítico, conducen a nuevos planteamientos para su estudio. Los principios del análisis geográfico avalan la vigencia y la preeminencia de los dos conceptos fuertes y los integra como piezas inseparables para una comprensión de la realidad de Europa. La integración política se ha convertido en referente ineludible en cualquier análisis territorial y socioeconómico de Europa occidental (VILLANUEVA, 1999). La identificación como región-sistema ha de utilizarse más como un principio explicativo que como un método y criterio delimitador del objeto de estudio, de sus límites y de su extensión territorial. Desde la Geografía la aportación al conocimiento de Europa se centra en su identificación como continente $\mathrm{y}$, a su vez, en su interpretación como espacio 
social; superando tanto la consideración sesgada derivada del enfoque subregional imperante como la consideración parcial del significado de los distintos subconjuntos (conjunto o espacio geopolítico, conjunto espacio geoeconómico) y entendiéndolos, en todo caso, como componentes específicos e interrelacionados de un concepto globalizado, de Europa como espacio geográfico.

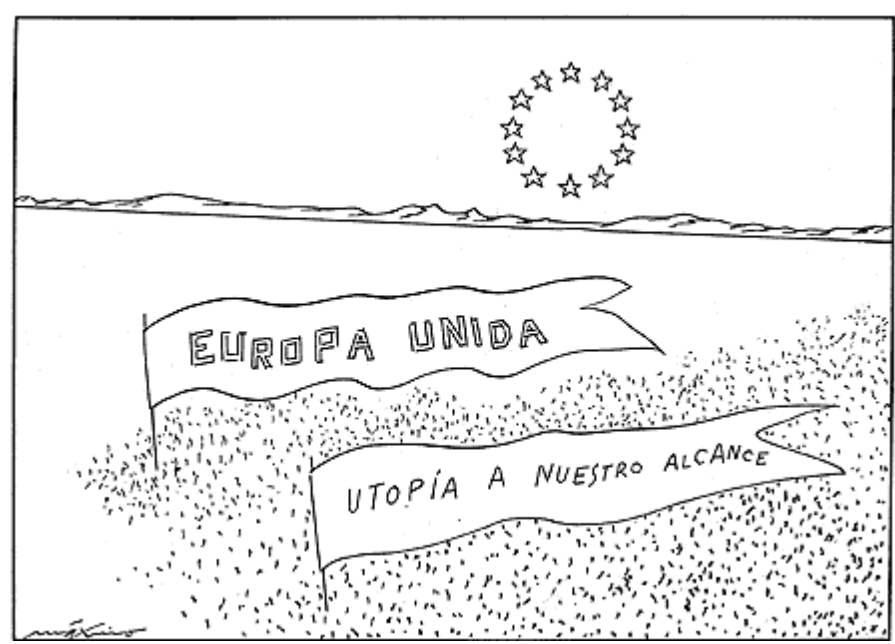

FIGURA 1.
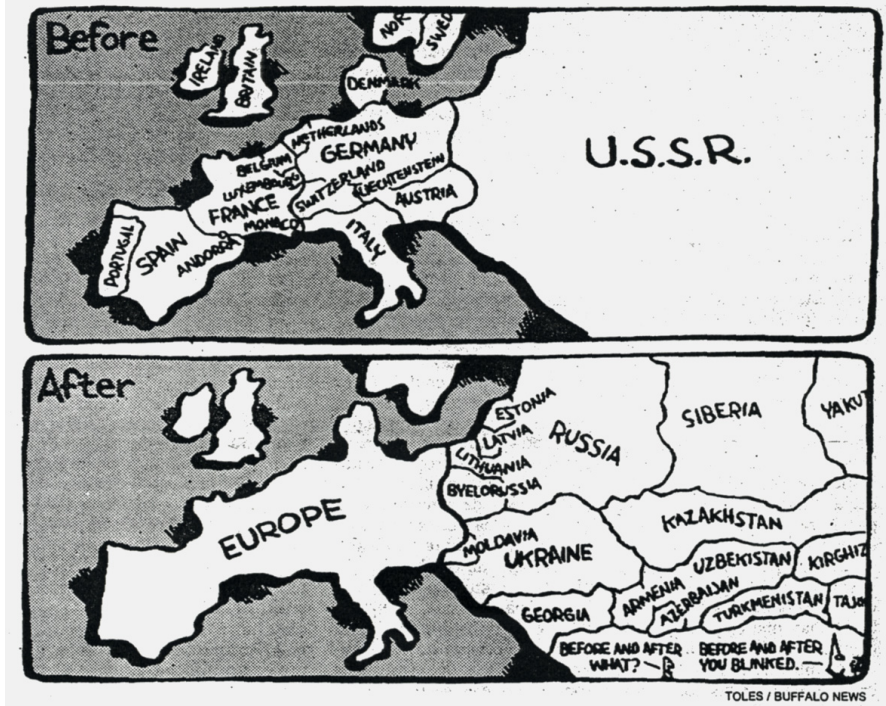

FIGURA 2. 
En el caso de los conjuntos geopolíticos, interesa subrayar que un Estado o agrupación de estados constituyen un conjunto espacial y, a la vez, un concepto geográfico. El concepto Estado y su relación espacial también han evolucionado tal como nos muestra la ciencia política. La diversidad de situaciones y de estadios evolutivos permite distinguir en el mapa básicamente tres tipos de Estados: premoderno, moderno, posmoderno. El premoderno se define por su situación caótica y el uso de la fuerza para su supervivencia. El Estado moderno se mantiene intransigente en la defensa de los principios de soberanía y de no injerencia, así como el monopolio de la fuerza y dirigen su política exterior en busca de la hegemonía o un equilibrio de poder. Los ejemplos mas representativo de este tipo de estado son Estados Unidos, Rusia, China, India, Pakistán, Israel, Turquía y muchos otros. El postmoderno se caracteriza por ejercer la soberanía de una manera tan flexible que la comparten, por integrarse en organizaciones supranacionales que regulan la injerencia de unos en los asuntos internos de los otros, por renunciar al uso de la fuerza entre ellos y por buscar la seguridad a través de la mutua vulnerabilidad. Es una situación propia de Canadá y Japón. Pero, sobre todo, de la mayoría de los estados europeos y en particular de los actuales y futuros miembros de la Unión Europea, constituyendo un rasgo nuevo de la estructura política europea que se proyecta sobre el mapa geopolítico en construcción.

Europa inició durante el siglo XX un camino hacia la integración continental, vertebrado económicamente y políticamente por la Unión Europea. En realidad se puede hablar de la pervivencia de procesos contrapuestos y de la integración a distintas escalas: la articulación de procesos a distintos niveles como opción para posibilitar las distintas inercias: unión-división, corrientes nacionalistascorrientes supranacionalistas. Estos procesos dibujan unos espacios geopolíticos y geoeconómicos y se traducen en representaciones cartográficas los cambios de sistemas y de la construcción de nuevas escalas de gobernación y regulación.

Los factores determinantes de estos complejos procesos son diversos, destacando entre ellos los denominados "factores externos". El proceso de construcción política de Europa no es ajeno ni en tiempo ni en forma a lo que ocurre y se decide en el resto del mundo, a las relaciones internacionales en todas direcciones y escenarios. Incluso esta interdependencia se establece en clave de "temor" al enemigo exterior. En este sentido cabe recordar que, por ejemplo, los historiadores han explicado la estrecha relación entre la Segunda Guerra Mundial y sus consecuencias y el surgimiento de la necesidad del proyecto de construcción económica y política de Europa occidental. Otra referencia más cercana es el desmoronamiento de la Unión Soviética y la hipótesis del "miedo" a la evolución del espacio postsoviético y sus consecuencias políticas y económicas como factor impulsor de la aceleración de 
los procesos de ampliación y profundización política de la Unión Europea; temor a un escenario de inestabilidad, temor al desequilibrio político-social provocado por posibles cambios de régimen político de países "frontera", como Turquía. En este caso, se puede citar como ejemplo, a raíz de los atentados terroristas de noviembre de 2003 en Turquía, las declaraciones de algunos países miembros de acelerar las conversaciones con este país para facilitar su ingreso en la UE. Se reconoce en definitiva, que el futuro mapa de Europa no será determinado solamente por los europeos, sino que pesan mucho las herencias de la división de Europa entre la OTAN, el Pacto de Varsovia y los estados neutrales y las implicaciones de las ambiciones neo-imperialistas y geopolíticas del complejo estatal y militar-industrial de los EUA (HUDSON, 2000, 423).

La construcción de la Unión Europea no ha sido tampoco ajena a la evolución y a las estrategias políticas, militares, económicas y territoriales de otros organismos continentales e internacionales durante los últimos cincuenta años, destacando por una parte las organizaciones de la Europa del Este y, por otra parte, la Organización Territorial del Atlántico Norte (OTAN). Conviene centrar la atención en el caso de la OTAN, puesto que también el 2002 fue el año de su gran ampliación y, en otro sentido, el significado que se le da a la hipótesis de que la presencia de la OTAN en el este del continente europeo antecede a la expansión de la UE hacia los países orientales de Europa.

En concreto, en el mes de noviembre de dicho año, en Praga los 19 jefes de estado acordaron su ampliación con el ingreso de Letonia, Lituania, Estonia, Eslovaquia, Rumania y Bulgaria a la OTAN, la Nueva OTAN dado la envergadura de la esta última ampliación que sin duda, según los analistas, tendrá ventajas políticas pero no militares, tal como se corroboró con la ampliación de 1999. Desde su creación la OTAN ha tenido diversas ampliaciones que le han permitido aumentar su influencia territorial y militar: primera ampliación, el 18/02/52, ingresan Grecia y Turquía; segunda ampliación, el 06/05/55, ingresa la República Federal Alemana; tercera ampliación, el 30/05/82, ingresa España; cuarta ampliación, el 12/03/99, ingresan la República Checa, Hungría y Polonia; y quinta ampliación, el 17/11/02, se acuerda el ingreso de 6 nuevos países: Letonia, Lituania, Estonia, Eslovaquia, Rumania y Bulgaria.

La segunda parte de la premisa señalada permite una reflexión a raíz de la noticia de que Georgia ha solicitado su ingreso en la OTAN. En este sentido, se puede afirmar que los países del Cáucaso nunca han sido tan occidentales -o lo que es lo mismo, tan "europeos"- como ahora. Esta condición se fundamenta tanto en la dinámica derivada de la desmembración de la URSS y el juego de influencias geopolíticas como en los intereses energéticos de la región (el petró- 
leo del Caspio y su conducción mediante oleoductos que atravesarán estos territorios, con presencia de empresas occidentales). En definitiva, esta "relación" con "occidente" se fundamenta en la coincidencia de intereses internos y externos que tienen su origen en tanto en estrategias geopolíticas como geoeconómicas.

El contenido del análisis realizado, que ha incluido la descripción de los límites geográficos del Viejo Continente, la descripción de los cambios del mapa político europeo y la descripción de las ampliaciones de la UE, permiten afirmar que el proceso de construcción política de Europa es un proceso inacabado, que se manifiesta en un mapa político dinámico, en construcción. EMERSON (1999), en su ensayo sobre el "nuevo mapa de Europa", realiza una rigurosa identificación del escenario espacio-temporal y una completa sistematización de los componentes del proceso y de las hipótesis de futuro que pueden dibujar ese mapa inacabado bajo la premisa de que la dinámica de la integración europea es persistente y poderosa, como balance favorable de la dialéctica entre las fuerzas impulsoras y las fuerzas obstaculizadoras. EMERSON $(1999,289)$ se pregunta ¿qué mapa o mapas de Europa tiene que dominar, si es que tiene que dominar alguno?. Para responder analiza las fuerzas o fuentes de integración: históricas (geografía, cultura, percepciones); económicas (mercados, moneda, redistribución) y políticas (valores, poder, seguridad) y las fuentes o factores opositores o de conflicto, y concluye que la pugna se decanta hacia la dinámica de la integración. A partir de aquí surge el tema del argumento que ha de sustentar el mapa, el tema del modelo de organización institucional y su proyección territorial que ha de derivar de la relación entre poder y territorio. En este sentido, EMERSON $(1999,300)$ identifica tres paradigmas relevantes para configurar el mapa emergente de Europa (el paradigma federal, el paradigma cosmopolita y el paradigma de la gestión) y cuatro tendencias que rivalizan en cuanto al mapa de Europa que vaya a configurarse: la Europa de los bloques, la Europa de Bruselas (al margen de la UE no existe ningún otro mapa europeo de alcance amplio), la Europa de la seguridad y la Europa civil. Y la respuesta a la pregunta ¿cuál de estos mapas es el más deseable o el más probable?, es que los tres primeros seguirán siendo significativos y que, en cambio, el de la Europa civil (mapa paneuropeo del Consejo de Europa, sin los EE.UU. ni Asia central y con la UE como núcleo fuerte) es el más improbable si bien es el que se necesita con más urgencia.

\section{BIBLIOGRAFÍA CITADA}

AA.VV. (2003): Qué quiere ser Europa. Dossier número 6, Barcelona, La Vanguardia. 
BAYLINA, M. Y PRATS, M. (2001): «Geografia continental: Europa», en Pallarés, M. Tulla, A.F. (Coords): Geografia Regional, Barcelona, Edicions de la Universitat Oberta de Catalunya, pp. 133-176.

BERENTSEN, W.H. y DIEM, A. (2000): «Introducción», en BERENTSEN, W.H, Europa contemporánea. Un análisis geográfico, Barcelona, Editorial Omega, pp. 1-55.

BRU Puron, C.Mª. (1999): Diccionario de la Unión Europea, Madrid, Editorial Universitas.

CABRÉ, A. y Domingo, J. (1991): «La població d'Europa», en AA.VV. Geografia Universal, vol. 3. Europa I. Barcelona, Edicions 92, pp. 28-37.

CAstro Aguirre, C. de (2001): «Tras la búsqueda de la Europeidad. Mapas mentales de Europa conforme a la memoria social de los europeos», en Scripta Nova, num. 91, junio 2001

Derruau, M. (1958): L'Europe, Paris, Hachette, (edición española: Europa, Barcelona, Ed. Labor, 1972).

EMERSON, M. (1999): El nuevo mapa de Europa, Madrid, Alianza.

FERRÁs, R. (1990): Les Géographies Universelles et le monde de leur temps, Montpèllier, Reclus.

FOUCHER, M. et al. (dir.) (1994): La próxima Europa. Un ensayo sobre alternativas y estrategias para una nueva visión de Europa, Bilbao, Fundación BBVA.

GutiÉRreZ, J. (1997): Europa: historia de una idea, Barcelona, Salvat Editores.

HudSON, R. (2000): «One Europe or many? Reflections on becoming European», en Trans Inst Br Geogr, $\mathrm{N}^{\mathrm{o}} 25$, pp. 409-426. .

JORDAN, T.G. (1996): The European Culture Área. A systematic geography, Nueva York, Haper Collins College Publishers.

LÓPeZ PALOMEQUE, F. (2000a): «Los conceptos de Europa y la geografía regional», en LÓPEZ PALOMEQUE, F. (Coord): Geografia de Europa, Barcelona, Ariel, pp. 21-58.

LÓPEZ PALOMEQUE, F.(2000b): «Los conceptos frontera y Europa», en Las implicaciones de la Ampliación de la Unión Europea en el marco mediterráneo, Madrid, Consejo Federal Español del Movimiento Europeo, 121-130.

LÓPEZ TRIGAL, L. (1999): «Mudanza y percepción del mapa de Europa», en profesor Joan Vilà i Valentí. El seu mestratge en la Geografia Universitaria, Barcelona, Publicaciones de la Universitat de Barcelona, pp. 401-410.

MARTí-HeNNEBERG, J. (2002): «El mapa administrativo de Europa. Continuidad y cambio (1850-2000)», en Scripta Nova. Revista Electrónica de Geografia y Ciéncias Sociales, num, 113, mayo 2002. 
MÉNDEZ, R. y MOLINERO, F. (1998): Espacios y sociedades. Introducción a la geografía regional del mundo. Barcelona, Editorial Ariel.

NoGUÉ, J. (1997): «Les fronteres i el nacionalisme», en DoMINGO, J. y MALLART, Ll. (Ed), A l'entorn de la frontera, Barcelona, Oikos-Tau, pp. 27-38.

PlAZA GuTIÉRREZ, J.I. (1997): «Europa en mutación (el Viejo Continente en el tránsito intersecular y ante un nuevo milenio)»; en CABERO DIÉGUEZ, V. y PlAZA GUTIÉRREZ, J.I. (Coords.): Cambios regionales a finales del siglo $X X$; Salamanca, A.G.E.-Departamento de Geografía de la Universidad de Salamanca, pp. 239-282.

PLAZA GUTIÉRREZ, J.I. (2000a): «La estructura politíca: un mapa cambiante y un proceso inacabado», en LÓPEZ PALOMEQUE, F. (Coord.) (2000), Geografia de Europa. Edit. Ariel, Barcelona, pp. 125-153.

PLAZA GUTIÉRREZ, J.I. (2000b): «Desencuentros, conflictos y confrontaciones: fracturas sociales y bélicas en Europa», en LÓPEZ PALOMEQUE, F. (Coord) (2000): Geografia de Europa. Edit. Ariel, Barcelona, pp. 419-444.

PLAZA GUTIÉRREZ, J.I. (2000c): «La Unión Europea: forma y proceso de integración política y económica», en LÓPEZ PALOMEQUE, F. (Coord) (2000): Geografía de Europa. Edit. Ariel, Barcelona, pp. 543-565.

Rebagliato, J. (1994a): «Procés de formació de les dues Europes», Treballs de la Societat Catalana de Geografia, 38, 191-196.

REBAGLIATO, J. (1994b): «Canvis de fronteres a Europa durant el segle XX», en Treballs de la Societat Catalana de Geografia, $\mathrm{n}^{\circ} 37$, pp. 203-213.

SÁNCHEZ SÁNCHEZ, J. (1995): «Los Estados surgidos de la antigua Unión Soviética y su articulación territorial en torno a Rusia»; en Espacio, Tiempo y Forma; Serie VI: Geografía; t. 8, UNED, Madrid, pp. 193-228.

UnwIN, T. (Ed.) (1998): A European Geography, Longman, Singapur.

VICENTE I RUFÍ, J. (1993): «Construcción, deconstrucción y reconstrucción de Europa», en Boletín de la Asociación de Geógrafos Españoles, $\mathrm{n}^{\circ}$ 17, pp. 167-179.

VillanUeVA I MARGALEF, M. (1999): La Unió Europea. Societat i territori en el procés d'integració, Barcelona, Universitat Autònoma de Barcelona, Servei de Publicacions.

RESUMEN: En este artículo se analiza la formación del nuevo mapa político de Europa como resultado del proceso de construcción de la Unión Europea, el proyecto europeo de alcance continental con mayor trascendencia política y territorial. El concepto político de Europa es hoy día un concepto fuerte, generalizado y hegemónico en la percepción de lo que es Europa, hecho que está desplazando a las otras acepciones del conti- 
nente. El análisis de los distintos conceptos -en particular del geográfico y el político- y de sus proyecciones espaciales (mapas con límites y fronteras) constituye un contexto básico al que se hace referencia para una mayor comprensión de los cambios del mapa político del Viejo Continente, de la evolución de la estructura política de la Unión Europea y de sus límites y dimensión espacial.

PALABRAS CLAVE: Viejo Continente, Europa, Geografía, Construcción europea, Mapa político.

ABSTRACT: The aim of this paper is to explain the developement of the new political map of Europe as the result of the building process of the European Union, the actual European project of continental range with more political and territorial importance. The political concept of Europe is nowadays an strong, generalized and hegemonic concept within the perception about what Europe is, which is moving the other concepts about the continent. The analysis of the different meanings of the word Europe - particularly its geographical and political concept - its spatial proyections (maps with limits and borders) is a basic reference framework which is reported in this paper for a better comprenhension of the changes in the political map of Europe, the political structure evolution of the European Union and its limits and spatial dimension.

KEY WORDS: Continent, Europe, Geography, Policy, Map, Concept, Process.

$\boldsymbol{R} \boldsymbol{E} \boldsymbol{S U} \boldsymbol{M E}$ : Le présent article analyse la formation de la nouvelle carte politique de l'Europe qui résulte du processus de construction européenne, le projet européen à échelle continentale le plus important politiquement et territorialement. De nos jours, la notion de l'Europe politique est une notion solide, généralisée et hégémonique dans la compréhension de ce que l'Europe signifie, qui est en train de reléguer les autres notions du Continent au deuxième rang. L'étude des différents sens du mot Europe, notamment de la notion géographique et politique, ainsi que de ses projections dans l'espace (cartes avec délimitations et frontières) est un concept de base auquel on fait référence dans cet article pour mieux comprendre les changements dans la carte politique du Vieux Continent, l'évolution de la structure politique de l'Union européenne, de ses limites et de sa dimension géographique.

MOTS-CLÉS: Vieux Continent, Europe, géographie, construction européenne, carte politique.

RESUMO: Neste artigo analisa-se a formação do novo mapa político da Europa como resultado do processo de construção da União Europeia, o projecto europeu de alcance continental com maior transcendência política e territorial. O conceito político de Europa é hoje em dia um conceito forte, generalizado e hegemónico na percepção daquilo que é a Europa, facto que está a deslocar as outras acepções do continente. A análise dos distintos conceitos -em particular do geográfico e do político- e das suas projecções espaciais (mapas com limites e fronteiras) constitui um contexto básico a que se faz referência para uma maior compreensão das mudanças no mapa político do Velho Continente, da evolução da estrutura política da União Europeia e dos seus limites e dimensão espacial. 
PALAVRAS CHAVE: Velho Continente, Europa, Geografia, Construção europeia, Mapa político. 